\title{
On How to Deal with Chinese Companies Listed Overseas Risk
}

\author{
Hueping Huang* and Huemin Huang \\ Zhao Zhan College Zhao Zhan, Shan dong Province, China \\ Bing Tuan College Wu Jiao Quiz, Xing Jiang Province, China \\ *Corresponding author
}

\begin{abstract}
In The article, in AL Company's case the status quo of Chinese enterprises listed overseas is pointed out. It analyzes the risks and causes of overseas listing, such as the high cost of risk, enterprise undervalued risk, refinancing risk, Legal risks and regulatory risks. To propos ways to deal with the risks listed overseas is, such as to establish a correct attitude listed overseas; their own fully prepared; optimization of the company's internal control system, strengthen the financial system construction; choosing good reputation of local service agencies.
\end{abstract}

Keywords-Chinese companies; overseas listing; reasonable to avoid

\section{INTRODUCTION}

As the nineties of last century reform and opening up, domestic enterprises began to enter overseas markets and overseas listing is the most common way. Especially in recent years, the pace of development of economic globalization accelerates and national economies blend even more depth. More and more Chinese companies have to go abroad in overseas capital markets for seeking a good image in the international market, enhancing international competitiveness, expanding financing channels, seizing the opportunity to develop the international market,. However, due to domestic and international capital markets, differences in terms of economic policy and financial accounting system, and because the information asymmetry between foreign investors and the invested enterprises, enterprises relatively perfect internal control mechanisms and other factors, so Chinese enterprises are faced with a number of uncertain risks overseas listing. At the same time how to conduct overseas listing and financing in order to meet the growing financial needs of proper preparedness and response overseas market risk, which is the focus of the need to carefully analyze and consider before many enterprises listed overseas.

Chinese companies listed overseas are after five climaxes. From a manufacturing-based state-owned heavy industry overseas listing of the beginning, and later the high-tech industry has become the main force of overseas listing. Recently overseas listing of the new climax is in October 21, 2005 that the State Administration of Foreign Exchange issued "a notice related to State Administration of Foreign Exchange by Domestic Residents through Overseas Special Purpose Financing and Return Investment Foreign Exchange Administration issues." The note clears the approach and scope to Chinese overseas listed companies. Through a more rational and effective legal management, guiding domestic enterprises overseas financing in order to properly meet their own funding needs, so private enterprises broaden the channels for overseas listing, and thus private enterprises become the new wave of the main listed overseas. Thus, under the socio-economic background study on how companies dealing with the risks listed overseas has far-reaching significance.

Wherein, AL Company as a typical representative of Chinese companies' success listed overseas, whose success has a significant impact in the international markets listed. It not only successfully obtains financing, and expands the company's overseas popularity. It can be described as fame and fortune. Therefore, we analysis its risks and response measures listed overseas. This is a good reference value for other companies.

\section{THE STATUS OF CHINESE ENTERPRISES LISTED OVERSEAS ANALYSIS}

\section{A. AL Company Profile}

AL is an Internet company, whose business model is more full modernization and diversification. It mainly provides customers with a more convenient commodity circulation market. Since its inception, it has been leading in the forefront of e-commerce, e-business in a variety of categories (such as on-line payment, etc. B2B market) services for consumers so far. In recent years, it is to follow the market development oriented, active in the new media mobile phone, Internet and television services, and strives to provide consumers with more comprehensive services, and becomes a leader in the Internet industry. The Company puts customers first, unity and cooperation, embrace change, integrity, passion and dedication as the company's core values, and strive to achieve the first platform to share data, the highest happiness index of enterprises better vision.

September 20, 2014, AL Company listed on the New York Stock Exchange, the first day closing price of \$ 93.89, with respect to the issue price of $38.07 \%$ to the closing price, the market capitalization broke \$230 billion.

\section{B. An Overview of Chinese Enterprises Listed Overseas and Motivation}

With the growing strength of China's economy, Chinese enterprises have entered the international market and overseas market. At present, overseas listing of Chinese enterprises have 
a huge amount of financing, listed mainly in Hong Kong, more emerging enterprises and other characteristics [1]. Only in the first half of 2014, Chinese enterprises in overseas release total debt financing of about $\$ 55$ billion, if you count the Yuan certificates of deposit, the total amount of financing will reach \$ 90 billion. Compared to the 2013 full-year total to \$ 75 billion overseas financing, in 2014 foreign financing will be high. In addition, in 2014, in 96 enterprises listed overseas, there are 72 which listed in Hong Kong, accounting for $75 \%$ of the total, and another 15 in the United States, accounting for $15.6 \%$ of the total. And it is more listed companies for the Internet industry, manufacturing, real estate and financial sector, especially the most prominent Internet industry. During 2011 to 2014, there are 29 Chinese companies listed in the United States, where there are 18 Internet industry, accounting for $62 \%$ of the total. Moreover, in 2014 only AL Company financing amount is as high as $\$ 22$ billion, accounting for 84.6 percent, of Chinese companies listed the amount of financing in the US market in 2014, and 30\% of the US market the amount of financing in 2014.

However, the overseas market, although there are wellfunded, capital market maturity, market management and other excellent advantages relatively strict transparency, but in terms of the costs of listing and information disclosure there are also some disadvantages. In addition, some small and medium enterprises blind pursuit of international development, not mature enough to conduct overseas market. Although the early part of the financing can be obtained, but due to lack of business in product quality, management mechanism, internal control, etc., resulting in the latter part of the cost increasing, limiting the development of enterprises. This violates the mind of seeking overseas market and enhancing its overall strength force.

There are many high-quality companies which successfully listed on fame and fortune, such as China Life Insurance, Sian, and Badu, mobile and other enterprises. Their success has opened up a new road to the Chinese enterprises to enter the international market. They tell other firms: if companies want full sway on stage their own strength in international market, they must improve and strengthen themselves

Chinese enterprises overseas financing motivation has two main aspects: First, in order to meet the growing demand for funds to finance the absorption of foreign capital; the second is based on relatively well-developed international market standards, improve their own management mechanisms and capital structure. Of course, during the same time listed overseas can enhance their international reputation, to expand its influence in the international market rate and the like [2].

\section{OVERSEAS LISTING OF CHINESE ENTERPRISES ENCOUNTERED RISK TYPES AND REASONS}

\section{A. The Risks and Causes of the High Cost}

Companies listed overseas, will not avoid some related costs, including the cost of listing procedures, attorney fees, finance audit fees, underwriting fees, ongoing maintenance fees and other expenses, covering all aspects, and because of differences in various aspects of culture, language, etc, which will bring a variety of hidden costs. The biggest difference is that the addition of the listing fees is paid after the listing, while the foreign market is paid before the market. To a certain extent, this increases business overseas listing transaction costs. Cost is the focus of business concern, if not effectively controlling costs, a company will be difficult to maintain normal production and operation, thus listed company or upcoming business more cost-conscious level. Many listed companies have been successful but delisting because they can not afford the high cost. Such as Hewlett-Packard company in 2007 because they can not bear the high costs and the choice of the Nasdaq delisting. The cost is much higher than domestic rates listed which is prohibitive for many companies: the costs of listing on NASDAQ market rate of about $13 \%-18 \%$, with an average of about $15.5 \%$, about $12 \%$ of the New York Stock Exchange, the Hong Kong Venture board and motherboard market close to $10 \%$,however with only 3 percent of domestic [3]. In addition, maintenance costs later are also a risk. CBEH stock just because the excess can not afford the maintenance costs later and thus had to choose delisting at June 15, 2011, the end of the journey in the NASDAQ market.

AL company also faces high costs. The cost of legal advice is just as high as \$ 15.8 million, which was paid when Face book listed six times the legal costs in 2012. \$ 121.8 million in underwriting fees also make many enterprises sigh. Moreover, there are many other costs. Even with strong financial strength as backing, cost control of AL companies is under the foot work. It is 3 times to change the tender, trying to be more secure market.

\section{B. Risks and Causes of Undervalued Companies}

Due to the different cultural concepts, understanding of values is different in different regions, so the same product in different regions will have different values. Moreover some companies are too quick success, seeking to market faster and choosing to be offering too low a price-earnings ratio. In addition, as overseas investors for Chinese enterprises to understand the limitations and differences in domestic and international business model, management philosophy resulting value of the business has been seriously underestimated, and thus can not be a better time to finance. Traditional industries suffer, but emerging Internet and IT industry is not immune. For example, the first market share in global Venire, even with good profitability and good management mechanism, but still not optimistic about the foreign investors, only received \$ 87 million during that listed on the Nasdaq financing.

\section{Refinancing Risk and Causes}

After the successful listing of enterprises, refinancing is a problem to be faced. However, because many companies continue late difficult to maintain good profitability and is questioned overseas investors. It is difficult to obtain investment investors. In addition, the ownership structure, financing structure and capital structure can not be optimized, which will reduce their ability to refinance. Some traditional enterprises is the lack of awareness of their own to improve the management, but the blind expansion of production of products uncompetitive, ability to refinance naturally not being recognized. 


\section{Legal Risks and Causes}

Due to the different legal systems at home and abroad, it is difficult to adapt quickly for Chinese companies on overseas markets institutional rules. So mistakes in practice, it is very vulnerable to the complaint. Such as preparing listed companies, because of the lack of experience at the time of listing material is inadequate preparation, and information disclosure is not timely. Commercial credit problems are again questioned. Especially in recent years, the rapid rise of electricity providers, many enterprises enter the overseas market listing. But because of the particularity of e-commerce, the market is difficult to obtain comprehensive supervision. Thus inferior products are in this easy circulation, and thus subject to consumer complaints. Chinese enterprises in overseas markets as examples of complaints are not uncommon. China Life Insurance, future worries, Sian and other companies had since "put false information" and are complained.

AL Company, because of providing false information and fake branded goods transaction in March 2015, is questioned by the market, leading shares fell, suffering heavy losses.

\section{E. Regulatory Risks and Causes}

The reasons for too many companies having chosen to go overseas listing are because a strict and transparent regulatory system in overseas securities market. But for businesses which undoubtedly is a kind of pressure. As the Mainland market starts late, and development is not very mature, so in the management of listed companies is not a particularly strong binding. The early development of overseas securities markets has also been relatively mature and improves. The information disclosure requirements are even more stringent than Chinese, but the legal system is also relatively well, and naturally in the implementation of the system is very strict. So the intensity of the constraints listed companies is also very strong. Furthermore, in addition to strict supervision from the securities regulatory authorities, investors and social supervision all sectors of society is very transparent. So, unless the enterprise itself can guarantee that there is enough capacity to adapt to overseas strict supervision system, at any time you may encounter regulatory wind from all sides. There is risk of being prosecuted.

\section{CHINA'S ENTERPRISE RISK APPROACH TO DEAL WITH OVERSEAS LISTING}

\section{A. To Establish a Correct Attitude towards Overseas Listing}

Overseas listing is not appropriate for all businesses. Some of the traditional business due to restrictions of their own culture may be difficult to get the recognition of international investors. So if you want to fully integrated enterprise can be fully integrated into the international market. Not all businesses are suitable for listing, and not all businesses are suitable for the overseas market [4]. Some companies are not listed which may also be developed into an international enterprise. For example Lao gang ma and Hawaii and other companies, their awareness in the international community is not low than some of the overseas listed companies, even far more than a lot of overseas listed companies. Of course, if it thinks fit to overseas markets business, then the business should establish a long- term plan prepared, fully prepare to face the risk of preparation. Aim to the overseas market enhances to improve corporate governance, to seek long-term development, not just for financing purposes.

\section{B. Their Own fully Prepared}

\section{1) Do market research and cost-benefit analysis}

Many companies choosing to go overseas listing is because blind to follow suit. But if the foreign market is suitable for enterprise or overseas market, is the need to adapt rigorous research and analysis decision. For other family businesses do not mean for you. Every company has its own advantages and shortcomings. Although listed companies have been able to provide some good experience that will be business, but the market research is a step that can not be omitted. Previous research must be done for their own business standards. The standard is not necessarily suitable for them, so market research is the basis of whether the companies can successfully list.

The earliest, AL is selected for listing in Hong Kong. But because of the Hong Kong market and AL Company is not able to fully adapt. Although in the relevant listing costs, the Hong Kong market was significantly lower than the US market. However, if the company is not able to AL Hong Kong market the perfect combination, and then a magnificent battle this listing may be short-lived. Therefore, the Board of Directors of the AL Company final decides still listed in the United States, the New York Stock Exchange.

Also, the fundamental purpose of the enterprise market is to be able to good financing. If the proportion of the costs and benefits beyond the normal range, then the company listed will be no significance. Many Chinese enterprises overseas financing to the front are not ready, then that can not be listed on the trust of investors, and even withdraw from the market due to make ends meet. Sundeck in 2005 after listing, the stock was in the doldrums, very few excluding the cost of financing. A serious imbalance in the ratio of revenue and pointed bring enormous pressure companies which will undoubtedly hinder the development of enterprises. Instead, to do the cost-benefit analysis prior to the listing, a reasonable estimate of enterprise value, to develop a reasonable offering price listed issuers will make more smoothly.

AL Company before listing there are many people making all kinds of its valuation. AL from the company's development in recent years, both the advantages of its development or performance of the industry, which all with gives investors a good impression. So investors for its future are full of hope and affirmation. This makes the AL having relatively high market valuations, which will undoubtedly be the first phase of financing for the company AL bringing high expectations.

2) Optimize the asset structure and improve the success rate of the listing

In order to enable enterprises to meet international market standards, companies should actively strive to optimize the asset structure of enterprises, to develop a reasonable reform plan according to their own development. To purposeful plan 
reform work, try to achieve optimal corporate assets to strive for a more fair valuation at the time of listing.

AL company before in the market kicks not mature assets, and strives to perfect asset structure of the market. The AL's successful IPO and achieving high valuations undoubtedly confirms the correctness of the AL's management decisions.

\section{3) Select the listing venue and timing carefully}

Chinese have a saying called success must have "climate, geography, and people." Market-ready business is "people", then how to cobble together a "day" and "location" is to see the choice of the listing venue and timing. If selecting listed companies or enterprises in which the choice is not deep understanding of the industry's market listing in the industry downturn, then the amount of funding will be affected. Instead, the election of the time and place would be more likely to get the trust of investors, listed companies after the financing will be more convenient [5].

In fact, AL Company from creation in1999 to list in 2014 is through 15 years of history. In recent years, the increasingly rapid development of the Internet, AL Company especially is good developments in the company in recent years. In last year, it improved business performance which made a wonderful performance, annual revenues of 49.3 billion Yuan. In the first quarter was 85.6 billion Yuan, the second quarter was 10.77 billion Yuan, 11.01 billion Yuan, in the third quarter, and fourth quarter, 11.86 billion Yuan. Full-year net profit was of 22.08 billion Yuan. The first quarter was 4.22 billion Yuan, the second quarter was 4.45 billion Yuan, the third quarter was 4.97 billion Yuan, and the fourth quarter was 8.44 billion Yuan. On this basis, year after year of soaring revenue and net profit is particularly evident in recent years. Its international reputation is also growing proliferation. In this fairly bright moments listed, AL company is quite obvious to attract investors attention. In addition, AL Company listed in both Hong Kong and the choice of listing in the United States, Hong Kong's lower listing fees and the United States a broader international market, are a great temptation. Finally, because they can not reach an agreement with the Hong Kong market system and the choice of the United States, AL Company may have a better future.

Optimize the company's internal control system, strengthen the financial system construction

AL Company's success is because it's more mature internal management and control systems. AL is constructed by the company board of directors, management level and three internal control systems of various functional departments, focusing on the establishment of sales offices. It develops a variety of risk control measures and procedures, avoids the traditional marketing model, fully in accordance with its customer oriented the core concept of providing customer excellent and reasonable service. It Strengthens after-sales management, strengthen site supervision and at the same time improves their quality of service. The company's remuneration and incentive system be reformed so that more employees have a sense of ownership for enterprises to actively seek development of. AL's proven system of internal controls shows a high-quality corporate image, but also for its fight for a more bright future.

Meanwhile, the financial system is the heart of the enterprise. Strict accounting system and effective enforcement of corporate financial accounting system is a regulatory basis and guarantee. Disclosure of information on overseas markets more stringent requirements on the accounting information accuracy requirements are higher. So to strengthen the management of financial systems is able to effectively avoid some legal risk and regulatory risk because of illegal operations encountering.

AL Company strictly regulates the financial management system, active and effective provision of financial information in accordance with the relevant accounting system, which fully demonstrates the positive image of the company AL. More advanced financial assessment indicators and relatively reasonable accounting system for the performance levels and operational level of investor valuation of businesses provides a more clear and effective proof.

\section{Selecting a Good Reputation of Local Service Agencies}

Companies should understand the various systems of the market before the overseas listing, such as trading system, legal system, accounting system, information disclosure system. There is no effective understanding for many companies and have been legal proceedings. Only professional quality service agencies can provide enterprises with useful information and effective services as much as possible, because of their professional knowledge and expertise making them more aware of local regulatory systems.

Before entering the overseas listed companies, AL listed its services to law firms legal consulting fees of 97.96 million Yuan, and then by the PricewaterhouseCoopers accounting and auditing work, one of the big four accounting firms perform audits affairs. Its underwriting business is to break the traditional to an underwriting company based model, to be shared by the five underwriters underwriting group. Strong service team for the AL's success provides a solid basis for a strong market.

\section{REFERENCES}

[1] Chunghwa Lang, "On the market choose overseas listing of Chinese SME”. Southern Finance, 2008, pp.5-6.

[2] Rica Huang, "private enterprises listed overseas Obstacles and Countermeasures”. Era trade, 2007 , pp.12-13.

[3] YuJuan Jiang, "Private enterprises listed overseas study". Commercial modernization, 2005 , pp.23-24.

[4] Pin pin Lana and Xiao fen Wu, "Chinese private enterprises listed overseas risk aversion”. Finance and Economics of Guangdong college, 2007, pp.17-18.

[5] Xiao ling Goo, "On the private enterprises listed overseas risk prevention”. Modern business, 2012, pp.22-23. 